\title{
PRZEKŁAD POEZJI JAKO WYZWANIE DLA TŁUMACZA - NA PODSTAWIE WŁASNEGO DOŚWIADCZENIA TŁUMACZENIA WIERSZY DZIEWIËTNASTOWIECZNEGO FRANCUSKIEGO POETY LECONTE DE LISLE'A
}

\begin{abstract}
Zarys treści: Tematem artykułu są autorskie spostrzeżenia związane z przekładem poezji z języka francuskiego na język polski na przykładzie przekładu rymowanych wierszy Leconte de Lisle'a. Dziełem, w którym zostały zamieszczone wspomniane wiersze, jest zredagowany w języku francuskim i przetłumaczony przez autorkę artykułu na język polski, wraz z cytowaną w nim poezją Leconte de Lisle’a, doktorat polskiego filozofa Henryka Elzenberga z 1909 roku zatytułowany Le sentiment religieux chez Leconte de Lisle (Odczuwanie religii u Leconte de Lisle'a). Przedmiotem szczególnego zainteresowania autorki artykułu jest zagadnienie rymów i układu sylabicznego w przekładzie wierszy.
\end{abstract}

Słowa kluczowe: przekład literacki; tłumaczenie poezji; strategia tłumaczeniowa

W dotychczasowej pracy translatorskiej ${ }^{1}$ nie miałam jeszcze okazji tłumaczyć poezji. Nadarzyła się ona dopiero wraz z powierzeniem mi zadania przełożenia z języka francuskiego na język polski pracy doktorskiej wybitnego polskiego filozofa Henryka Elzenberga zatytułowanej Le sentiment religieux chez Leconte de Lisle (Odczuwanie religii u Leconte de Lisle'a). Hen-

${ }^{1}$ Jestem autorką przekładów z języka francuskiego na język polski następujących dzieł: P Hadot, Plotyn albo prostota spojrzenia, Kęty 2004; P. Ricœur, Refleksja dokonana. Autobiografia intelektualna, Kęty 2005; M. Conche, Filozofować w nieskończoność, Kęty 2007; H. Elzenberg, Odczuwanie religii u Leconte de Lisléa, Torun 2013 oraz M. Fattal, Słowa i czyny u Heraklita. O teoretycznych podstawach moralnego działania, „Archiwum Historii Filozofii i Myśli Społecznej”, t. 58, Warszawa-Toruń 2013. 
ryk Elzenberg uczynił z poezji Leconte de Lisle’a główne zagadnienie swojej dysertacji z uwagi na podejmowaną $\mathrm{w}$ niej tematykę filozoficzną i religijną. Tłumaczenia wierszy Leconte de Lisle’a podjęłam się z wielką nieśmiałością i świadomością, że praca ta to ogromne wyzwanie dla tłumacza, ale także z przeświadczeniem o potrzebie, a wręcz konieczności wykonania tego zadania. Wymagał bowiem tego przekład doktoratu Henryka Elzenberga, w którym cytowana poezja odgrywa znaczącą rolę. Jednocześnie, co warto na wstępie podkreślić, przekład wierszy nie był celem samym w sobie, gdyż wiersze stanowią - podobnie jak w oryginale - korpus rozprawy i służą potwierdzeniu i zilustrowaniu rozważań Henryka Elzenberga na temat tytułowego „odczuwania religii” u Leconte de Lisle’a. Na potrzeby przekładu przetłumaczyłam większość wierszy wspomnianego dziewiętnastowiecznego poety. Wyjątkiem są cytowane $\mathrm{w}$ języku polskim wiersze, które zostały przetłumaczone i zebrane w zbiorze: Leconte de Lisle, Poezje, wybrał J. Strasburger, Warszawa 1980 (por. Elzenberg 2013). Zanim przejdę do autorskich spostrzeżeń i uwag dotyczących przekładu poezji - co jest przedmiotem niniejszej pracy - chciałabym pokrótce przedstawić postaci Henryka Elzenberga i Leconte de Lisle’a.

Henryk Józef Maria Elzenberg (1887-1967) to polski filozof, aforysta, który zajmował się głównie etyką, estetyką, aksjologią i historią filozofii. W roku 1905 zdał w Genewie maturę i podjął studia z zakresu literatury francuskiej i starożytnej, a następnie filozofii na Uniwersytecie Paryskim. Praca Le sentiment religieux chez Leconte de Lisle (Odczuwanie religii u Leconte de Lisléa) stanowi pracę doktorską filozofa zredagowaną w 1909 roku na paryskiej Sorbonie. Henryk Elzenberg pracował m.in. na Uniwersytecie Warszawskim, Katolickim Uniwersytecie Lubelskim, Uniwersytecie Marii Curie-Skłodowskiej w Lublinie i Uniwersytecie Mikołaja Kopernika w Toruniu. (por. Tyburski 2006: 167-169).

Charles-Marie-René Leconte de Lisle (1818-1894) to francuski poeta, filozof, filolog klasyczny, tłumacz Iliady i Odysei oraz wierszy zebranych i tragedii antycznych, krytyk literacki romantyzmu, uznany za przywódcę nurtu zwanego parnasizmem, pesymista, nihilista i ateista, autor wyrażenia „sztuka czysta” i propagator hasła „sztuka dla sztuki”. Jeden z najwybitniejszych poetów XIX wieku we Francji, zwany „poetą religii”, nawiązujący do Biblii i mitologii greckiej, zafascynowany filozofią buddyjską i hinduizmem. Był mistrzem duchowym m.in. takich poetów jak Stéphane Mallarmé i Sully Prudhomme. Cenił go Arthur Rimbaud, Paul Verlaine, Rainer Maria Rilke czy Charles Baudelaire. Jest autorem parnasistowskiego programu poetyckiego, którego główny postulat głosi zerwanie ze zbyt emocjonalnym i subiektywnym stylem romantyzmu i skupienie się na obiektywnej i filozoficznej anali- 
zie świata. Leconte de Lisle był także członkiem Akademii Francuskiej (Académie française). To autor poezji zebranej w tomach zatytułowanych Poèmes antiques (1852), Poèmes et Poésies (1855), Poèmes barbares (1862) i Poèmes tragiques $(1884)^{2}$.

Johann Wolfgang von Goethe powiedział: „Kto poetę chce zrozumieć, musi pójść w kraj poety" (za: Skibińska 1999: 201). Jednak to zadanie nie jest takie proste, jakby się mogło wydawać. Często bowiem już ów poetycki świat nie istnieje lub zmienił się nie do poznania. Dlatego też tak odważnym zadaniem staje się podjęcie przekładu wielkich dzieł, do których zaliczyć można także wiersze „ojca parnasizmu” - Leconte de Lisle’a. Elżbieta Skibińska w kontekście przekładu Pana Tadeusza na język francuski wypowiada następujące słowa:

Tłumaczenie każdego wybitnego utworu zanurzonego w kulturze narodowej, odwołującego się do kulturowego kodu jako narzędzia komunikacji czytelników należących do konkretnej społeczności, stanowi zadanie niezmiennie ambitne - można wręcz zastanawiać się, czy wykonalne, jeśli przypomnieć, że różnice kulturowe są uważane za jedną z przyczyn nieprzekładalności. [...] To właśnie nasycenie utworu specyficznie polskimi odniesieniami kulturowymi decyduje o tym, że, jak pisze Aleksander Wit Labuda, „kto się bierze za przekład, ten swą duszę może polecić opiece chyba tylko Syzyfa" (Skibińska 1999: 8).

Natomiast Stanisław Barańczak w Ocalone w tłumaczeniu zamieszcza „Mały, lecz maksymalistyczny manifest translatologiczny albo: Tłumaczenie się z tego, że tłumaczy się wiersze również w celu wytłumaczenia innym tłumaczom, iż dla większości wierszy nie ma wytłumaczenia" (Barańczak 1994: 13). Ów „Manifest” zdaje sprawę z trudności związanej z zadaniem przełożenia poezji z języka wyjściowego na język docelowy. Fakt, że poezja jest niewątpliwie jednym $z$ najtrudniejszych do tłumaczenia typów tekstu, wynika przede wszystkim $\mathrm{z}$ konieczności poprawnego zinterpretowania $\mathrm{w}$ języku docelowym zarówno formy, jak i treści. W moim przekładzie poezji wyszłam z kilku podstawowych założeń, których starałam się przestrzegać w ciągu całego procesu przekładu:

1. Poszanowanie składnika „obcości” w przekładzie, zaakceptowanie „innego” („obcego”) (Skibińska 1999: 12):

${ }^{2}$ Notka biograficzna Leconte de Lisle’a cytowana w nieco zmodyfikowanej formie za: Elzenberg 2013. 
Dziś zarówno tłumacze, jak i teoretycy przekładu wiedzą, że różnice między językami, a w jeszcze większym stopniu różnice między kulturami sprawiają, że to, co przez lata było uważane za cel i wymóg dobrego przekładu - czyli uzyskanie ekwiwalencji semantycznej (denotatywnej) i ekwiwalencji pragmatycznej (konotatywnej) - jest w gruncie rzeczy niespełnialnym marzeniem. Powiedzenie traduttore-tradittore ma właściwie charakter pleonazmu, bo „zdrada” jest niejako wpisana w działanie tłumacza (Skibińska 1999: 202).

2. Tłumaczenie poezji jest zawsze aktem jej interpretacji, a więc aktem hermeneutycznym, gdyż tłumaczenie jako czynność przeniesienia tekstu w inny język jest tu utożsamiana z czynnością wyjaśniania opartego na rozumieniu i rozstrzyganiu (por. Barańczak 1994: 15):

Interpretacja translatorska w ostatecznym efekcie stwarza analogiczny - analogicznie funkcjonujący - tekst w innym języku etnicznym. Gotowe tłumaczenie jest jak gdyby namacalnym, wymiernym dowodem, że się idealnie zrozumiało oryginał. Tak idealnie, że jest on w stanie funkcjonować w języku B i kulturze literackiej B tak samo jak w języku i kulturze A (Barańczak 1994: 15).

3. Tłumacz powinien potrafić wskazać to, co w utworze poetyckim uznaje za siedzibę czy nośnik sensu lub za czynnik sensotwórczy, który jest na tyle ważny, że - jak pisze Stanisław Barańczak - „domaga się” od tłumacza bezwarunkowego ocalenia w procesie przekładu. Także w tym znaczeniu tłumaczenie wiersza jest jego interpretacją również w sensie rozstrzygania, wyboru najmniejszego zła, znajdowania najbardziej przybliżonych ekwiwalentów, rezygnowania z czegoś w celu ocalenia czegoś innego. Zatem tłumacz powinien odpowiedzieć sobie na pytanie, co musi w przekładzie ocaleć i wyznaczyć kryteria przyjęte $\mathrm{w}$ tym procesie decyzyjnym, które nie mogą być arbitralne (Barańczak 1994: 18).

W moim przypadku na to, co musiało w przekładzie wierszy Leconte de Lisle’a ocaleć, wpłynęła bez wątpienia sama charakterystyka owych wierszy wywodzących się z prądu literackiego zapoczątkowanego we Francji w XIX wieku zwanego parnasizmem, szczególnie związanie parnasistów z klasycyzmem, upodobanie antycznego ładu oraz kult formalnej doskonałości w poezji ${ }^{3}$.

Starałam się zatem zachować ducha poezji francuskich parnasistów, m.in. ich niechęć do bezpośrednich wyznań wszechobecnych w wierszach roman-

${ }^{3}$ Na temat parnasizmu por. Adamski 1966: 198; Jarrety 2001: 421-423; Jarrety 1997: 349-258; Lam 1933: 473-474; Orizet 2007: 1035-1036. 
tyków, dążenie do obiektywnego jednoznacznego opisu, poszukiwanie motywów w kulturach archaicznych i egzotycznych. Ważne dla mnie było także to, że parnasiści określali swoją pracę nad tekstem jako działanie rzemieślnika, który precyzyjnie dopracowuje każdy element dzieła. Zatem dołożyłam starań, by także forma wiersza w języku docelowym była harmonijna, symetryczna i misterna, a co za tym idzie - by język poezji był dopracowany i przemyślany.

4. W tłumaczeniu wierszy ważny jest kontekst utworu, czyli m.in. środowisko, w którym autor przebywał w trakcie tworzenia, co uwidacznia się w podmiocie, którego „słyszymy” w wierszu, języku i doborze słów, składni, metaforyce oraz elementach percypowanych za pośrednictwem zmysłów. Istotne są efekty dźwiękowe: rymy, asonanse, konsonanse i aliteracje, rytm czy rozłożenie akcentów (zob. Głowiński i in. 1967: 215, 216, 149).

Parnasiści kładli nacisk na ukształtowanie formalne tekstu poetyckiego: na dbałość wersyfikacyjną, rymy, idealną rytmizację (por. Głowiński i in. 1998: 493). Pozwoliło im to w pełni zapanować nad budową utworu. Właśnie ten element stał się w moim przekładzie wierszy najważniejszy: zachować formę wierszy i podporządkować jej treść. Uważam, że w przypadku przekładu wierszy parnasisty Leconte de Lisle’a, tłumacz powinien dołożyć starań, by forma wiersza była jak najbliższa oryginałowi - dopracować układ rymów i układ sylabiczny.

Jeśli chodzi o układ sylab, to w oryginale wiersze Leconte de Lisle’a zostały zapisane aleksandrynem, francuskim wierszem dwunastozgłoskowym, jambicznym, akcentowanym na szóstej zgłosce, po której występuje średniówka (por. Jasińska 1956: 353). W języku polskim forma ta jest bardzo rzadka ze względu na trudności w uzyskaniu czystego wersu jambicznego oraz w bardzo nienaturalnie po polsku brzmiącym układzie wersowym $\mathrm{z}$ akcentowaną ostatnią sylabą. W tłumaczeniach na język polski aleksandryn zazwyczaj oddawany jest innym wersem, zwykle trzynastozgłoskowym o mieszanej stopie. Dlatego też zgodnie z przyjętą tradycją francuski aleksandryn przełożyłam na polski wers trzynastozgłoskowy (por. Kopczyńska 1956: 380).

5. Niewątpliwie najkorzystniejszą sytuacją dla przekładu poezji byłaby taka okoliczność, w której na miejscu tłumacza wierszy znalazłby się tzw. zawodowy poeta, który znając się na rzeczy, dysponowałby wystarczającą wiedzą językową (w tym przypadku znajomością języka francuskiego) i przełożyłby poezję na język polski. Zdarza się to jednak nader rzadko.

Wszystkie powyższe założenia towarzyszyły mi w trakcie przekładu wierszy Leconte de Lisle’a zamieszczonych przez Henryka Elzenberga w jego pracy doktorskiej. Układ rymów w poezji Leconte de Lisle’a, który stanowi przedmiot niniejszej analizy, ilustrują poniższe wybrane fragmenty wierszy przetłumaczonych przeze mnie na język polski: 
1. Miałem widzenie, mój Panie, olśniewające!... ...O świątynio, gdzie ma myśl chwilę oślepiona, Drżąca, zapomniała, że ziemia oddalona ...

Twoi kapłani radzi, z wysokości śmiali,

Moje serce pieśniami o raju przelali!...

...I szukałem Ciebie w ogromnym upojeniu,

W tych wspaniałych ścianach, na twarzach w otępieniu

W tych hymnach harmonią i miłością nabrzmiałych,

W tych cudownych dniach tysiącem słońc doskonałych;

I szukałem Ciebie, cichego i mądrego,

I nie ujrzałem, Panie, oblicza Twojego!

La Recherche de Dieu ${ }^{4}$

2. Panie, w czasie całego mego wędrowania, Wieczne pragnienie chłonęło czas bytowania. Wciąż w stronę Twej twarzy i uczucia Twojego Wznosiłem ramiona kochanka żarliwego, I znalazłem tylko żółć i rozczarowania W wiecznym kielichu, karmie mego obłąkania. La Recherche de Dieu 6

3. Cnota, ból, myśl, nadzieja, wyrzuty sumienia, Miłość, co cały wszechświat zwinnie przemierzała, Amour, qui traversais l'univers d'un coup d’aile, Czymże się staliście? Czymże się dusza stała? Czemu dusza zmarłych jest wyrwana z milczenia? Dernières Visions, [Poèmes barbares $]^{8}$

4. Jakiś potwór nienasycony pożarł życie. Świecące gwiazdy niebios, poświadczycie także! Drżyjcie teraz, bo tutaj na dole, jednakże, Straszna zjawa, potwór najadł się należycie. Dernières Visions, [Poèmes barbares $]^{10}$

5. Więc nasi bogowie to marzenie? Kłamali? Zobacz, jaki nieśmiertelny świat nam oddali, Żywy symbol, harmonijne dzieło spłodzone Dowód ich geniuszu, na ich obraz stworzone, Godne kultu wiecznego, po to je wydano By je w porządku i jasności rozwijano! Hypatie et Cyrille ${ }^{12}$

\footnotetext{
${ }^{4}$ Elzenberg 2013: 54.

5 Elzenberg 1909: 51.

6 Elzenberg 2013: 66.

7 Elzenberg 1909: 64.

8 Elzenberg 2013: 80.

9 Elzenberg 1909: 81.

10 Elzenberg 2013: 80.

11 Elzenberg 1909: 80.

12 Elzenberg 2013: 176.

13 Elzenberg 1909: 192.
}

1. J'eus une vision, Seigneur, éblouissante!...

...O temple où ma pensée un instant éblouie, Frissonnante, oublia la terre évanouie...

Tes prêtres radieux, du haut des fûts hardis, Ont versé dans mon cour les chants du paradis!...

...Et je vous ai cherché dans cette ivresse immense, Dans ces murs éclatants, sur ces fronts en démence,

Dans ces hymnes gonflés d'harmonie et d'amour, Dans ces mille soleils, d'un mystérieux jour;

Et je vous ai cherché, vous, le calme et le sage, Et n'ai point rencontré, Seigneur, votre visage! La Recherche de Dieu ${ }^{5}$

2. Seigneur, dans tout le cours de mon pèlerinage, Un désir éternel a consumé mon âge. Toujours vers votre face et votre sentiment J'ai tendu les deux bras comme un fiévreux amant, Et je n'ai rien trouvé que le fiel et la lie Au calice éternel quépuisait ma folie. La Recherche de Dieu

3. Vertu, douleur, pensée, espérance, remords, Qu'êtes-vous devenus? Lâme, qu'a-t-on fait d'elle? ? Qu'a-t-on fait de l'esprit silencieux des morts? Dernières Visions, [Poèmes barbares] ${ }^{9}$

4. Un monstre insatiable a dévoré la vie, Astres resplendissants des cieux, soyez témoins! C'est à vous de frémir, car ici-bas, du moins, Laffreux spectre, la goule horrible est assouvie. Dernières Visions, [Poèmes barbares ${ }^{11}$

5. Nos Dieux nétaient-ils donc qu'un rêve? Ont-ils menti?

Vois quel monde immortel de leurs mains est sorti, Ce symbole vivant, harmonieux ouvrage Marqué de leur génie et fait à leur image, Vénérable à jamais, et qu'ils n'ont enfanté Que pour sépanouir dans l'ordre et la clarté! Hypatie et Cyrille ${ }^{13}$ 
6. I, wybranego rodu oddani boskości,

Subtelni Wieczni w nich Ichoru przepływanie, Heroizmu, Piękna, Poezji i Mądrości

Na złotym Bruku przy Kronosie zasiadanie.

La Paix des Dieux ${ }^{14}$

7. Wszystko zniknęło bez odgłosu ni wspomnienia,

Nie ma młodego i pięknego świata siły.

Wieki pchnęły w czeluście tej samej mogiły

Boskie złudzenie i pomruki pokolenia.

Dernières Visions, [Poèmes barbares] ${ }^{16}$

8. Wartości nieśmiertelnych ważne nauczanie Płynie z twojej wargi w głąb serc zaczarowanych; Galilejczyków dla cię skrzydeł pożądanie

Co zrzekli się Boga dla twych bogów kochanych. Hypatie ${ }^{18}$

9. Słońce osuszy grobu pod wodą czeluści? Cóż mają innego niźli trwanie skończone? Ach! wiemy - w niepamięć zostaną oddalone... Panie, mroków Twej otchłani nic nie opuści. La Recherche de Dieu ${ }^{20}$

10. Daj szlachetny pokój mędrcowi! Uczyń Boga! Jak dźwięk, który się skończy, jak błysk, który minie Od czasu, cyfr i od przestrzeni uwolnij mnie, I zrzucając na mnie Twój ciężar zgromadzony, Pozwól na odpoczynek życiem zakłócony. Les Sandales d'Empédocle 22

11. Gdy najwyższy ze szczytów ze swymi pianami, 11. Quand le plus haut des pics eut bavé son écume, Thogorma, syn Elama, z przerażenia padł z nóg, Żyje Kain Mściciel, to jest nieśmiertelny Wróg Jahwe, który przechadzał się, złowrogi, z mgłami, Tam, gdzie wyłania się widoczny w połowie Łuk. Qaïn ${ }^{24}$
6. Puis, les divins amis de la race choisie, Les Immortels subtils en qui coulait l'Ikhôr, Héroïsme, Beauté, Sagesse et Poésie Autour du grand Kronides assis au Pavé dor. La Paix des Dieux ${ }^{15}$

7. Tout, tout a disparu, sans échos et sans traces, Avec le souvenir du monde jeune et beau. Les siècles ont scellé dans le même tombeau Dernières Visions, [Poèmes barbares $]^{17}$

8. Le grave enseignement des vertus éternelles Sépanchait de ta lèvre au fond des cœurs charmés; Et les Galiléens qui te rêvaient des ailes

Oubliaient leur Dieu mort pour les Dieux bien-aimés. Hypatie $^{19}$

9. Quel soleil séchera leur tombe diluvienne? Que sont-ils au delà de leur cours accompli? Hélas! Ce qu'on sait d'eux, c'est qu'ils vont à loubli... Seigneur, de votre abîme il n'est rien qui revienne. La Recherche de Dieu2 ${ }^{1}$

10. Donne une paix sublime au sage! Fais un Dieu! Comme un son qui finit, comme un éclair qui passe, Affranchis-moi du temps, du nombre et de l'espace, Et, rejetant sur moi ton poids amoncelé, Que je rentre au repos que la vie a troublé. Les Sandales d'Empédocle $e^{23}$ Thogorma, fils d'Elam, d'épouvante blêmi, Vit Qaïn le Vengeur, l'immortel Ennemi D'Iahvèh, qui Marchat, sinistre, dans la brume, Vers l'Arche monstrueuse apparue à demi. Qaïn ${ }^{25}$ L'illusion divine et la rumeur des races.

\footnotetext{
14 Elzenberg 2013: 159.

5 Elzenberg 1909: 173.

16 Elzenberg 2013: 80.

17 Elzenberg 1909: 81.

18 Elzenberg 2013: 158.

9 Elzenberg 1909: 173.

Elzenberg 2013: 84.

1 Elzenberg 1909: 85.

2 Elzenberg 2013: 85.

3 Elzenberg 1909: 87.

4 Elzenberg 2013: 207.

5 Elzenberg 1909: 229.
} 
12. A teraz, o umarli, mękę skończyliście, Smakujecie szczęścia, o którym marzyliście? Czy Pan dotrzymał swoją przysięgę wieczności? A wasza dusza bez przykrywki doczesności, Jak promyk wznosi się do nieba niebieskiego, Dołączyć zdołała do Boga wspaniałego? Nikt nie wie: cóż znaczy, o wzniosłe pokolenie, Cóż znaczy przebudzenie? Wielkie to marzenie. Les Ascètes ${ }^{26}$

13. I wy, radosne słońca młodych lat minionych, Wy, lśniące noce otwartej nieskończoności, Co przelałyście wasz blask do mórz oświetlonych, Umysł, co was stworzył, ciągnie was ku nicości. L'Illusion suprême $e^{28}$
12. Et maintenant, ô morts, le supplice achevé, Goûtez-vous le bonheur que vous aviez rêvé? Le maître a-t-il tenu sa promesse éternelle? Et votre âme, brisant l'enveloppe mortelle, Comme un rayon léger qui remonte au ciel bleu, S'est-elle réunie à la splendeur de Dieu?

Nul ne sait: mais qu'importe, ô race magnanime, Qu'importe le réveil? Le songe était sublime.

Les Ascètes $^{27}$

13. Et vous, joyeux soleils des naïves années, Vous, éclatantes nuits de l'infini béant,

Qui versiez votre gloire aux mers illuminées, L'esprit qui vous songea vous entraîne au néant. L'Illusion suprême ${ }^{29}$

W tłumaczonej na język polski i cytowanej powyżej poezji Leconte de Lisle’a wyzwaniem stało się dla mnie zachowanie oryginalnych rymów. $\mathrm{W}$ przetłumaczonych wierszach Leconte de Lisle’a mamy do czynienia $\mathrm{z}$ następującymi typami rymów ${ }^{30}$ :

1) w zależności od umiejscowienia: w większości przypadków są to rymy końcowe; zarówno rymy parzyste - przypadek fragmentów wierszy: 1 , 2, 5, 10, 12, np.

śmiali-przelali (wiersz 1),

upojeniu - otępieniu (wiersz 1),

wędrowania - bytowania (wiersz 2),

Twojego - żarliwego (wiersz 2),

kłamali - oddali (wiersz 5),

spłodzone - stworzone (wiersz 5),

minie - mnie (wiersz 10),

zgromadzony - zakłócony (wiersz 10),

skończyliście - marzyliście (wiersz 12),

wieczności - doczesności (wiersz 12),

jak i przeplatane (krzyżowe) - przypadek fragmentów wierszy: 6, 8, 13, np. boskości - Mądrości (wiersz 6),

przeplywanie - zasiadanie (wiersz 6),

nauczanie - pożądanie (wiersz 8),

${ }^{26}$ Elzenberg 2013: 114.

${ }^{27}$ Elzenberg 1909: 121.

28 Elzenberg 2013: 106.

29 Elzenberg 1909: 111.

${ }^{30}$ O typach rymów, zob. Głowiński i in. 1998: 487-492; Głowiński i in. 1967: 211-217 oraz Pszczołowska 1972: 13-17. 
zaczarowanych - kochanych (wiersz 8),

minionych - oświetlonych (wiersz 13),

nieskończoności - nicości (wiersz 13)

i okalające - przypadek fragmentów wierszy: $3,4,7,9,11$, np.

sumienia - milczenia (wiersz 3),

przemierzała - stała (wiersz 3),

$\dot{z} y c i e$ - należycie (wiersz 4),

takj̇e - jednakize (wiersz 4),

wspomnienia - pokolenia (wiersz 7),

siły - mogiły (wiersz 7),

czeluści - opuści (wiersz 9),

skończone - oddalone (wiersz 9),

pianami - mgłami (wiersz 11),

nóg - Wróg (wiersz 11).

2) w zależności od akcentu:

a) rymy żeńskie - $\mathrm{z}$ akcentem paroksytonicznym, np. sity - mogity (wiersz 7),

b) rymy męskie - z akcentem oksytonicznym, np. nóg - wróg - Łuk (wiersz 11),

c) rymy dokładne, np. także - jednakże, życie - należycie (wiersz 4), nieskończoności - nicości (wiersz 13),

d) rymy niedokładne: asonans, np. spłodzone - stworzone (wiersz 5), i konsonans, np. minie - mnie (wiersz 10),

e) rymy gramatyczne - np.

- czasowniki: śmiali - przelali (wiersz 1), przemierzała - się stała (wiersz 3), kłamali - oddali, wydano - rozwijano (wiersz 5), skończyliście - marzyliście (wiersz 12),

- rzeczowniki: upojeniu - otępieniu (wiersz 1), wędrowania - bytowania, rozczarowania - obłakania (wiersz 2), sumienia - milczenia (wiersz 3), wspomnienia - pokolenia (wiersz 7), doczesności - wieczności (wiersz 12) itd.,

- przymiotniki: np. nabrzmiałych - doskonałych (wiersz 1), twojego - żarliwego (wiersz 2), zgromadzony - zakłócony (wiersz 10),

f) rymy niegramatyczne - np. $\dot{z} y c i e$ - należycie (wiersz 4), czeluści opuści (wiersz 9), minie - mnie (wiersz 10).

Największym wyzwaniem związanym z przekładem poezji Leconte de Lisle’a było dla mnie zachowanie w tłumaczonych na język polski wierszach ducha dziewiętnastowiecznej epoki oraz filozoficzno-religijnego wymiaru 
przekładanej poezji. Temu właśnie podporządkowałam dobór środków leksykalno-stylistycznych i struktur gramatycznych w przekładzie. Poeci w swoich wierszach nie przywiązują zbyt dużej wagi do ścisłego przestrzegania reguł gramatycznych, zgodnie ze słowami Fernando Pessoa: „Niech przestrzega gramatyki, kto nie potrafi pomyśleć tego, co czuje" (za: Brzozowski 2011: 131). Oczywiście wszelkie zmiany gramatyczne w tekście docelowym są możliwe, ponieważ w tym przypadku ważniejsze jest przekazanie treści utworu. Dlatego każda decyzja tłumacza o zmianie gramatycznej formy utworu jest uzasadniona, pod warunkiem, że nie wpływa ona na znaczenie frazy. Kierowałam się tą zasadą przekładając wiersze Leconte de Lisle’a. Największych modyfikacji w porównaniu $\mathrm{z}$ tekstem oryginalnym dokonałam w strukturach gramatyczno-stylistycznych. Posiłkując się właśnie cytowaną powyżej, reprezentatywną poezją Leconte de Lisle’a, chciałabym na kilku przykładach zilustrować, jakim transformacjom najczęściej poddałam tekst oryginału.

Modyfikacje polegały przede wszystkim na następujących transformacjach: substytucji, inwersji, amplifikacji oraz redukcji, co potwierdzają poniższe przykłady.

\section{Substytucja}

1) wyrażenie przyimkowe $\rightarrow$ rzeczownik

Ont versé [tes prêtres radieux] dans mon cour les chants du paradis!...

Moje serce [twoi kapłani radzi] pieśniami o raju przelali!... (wiersz 1)

2) czasownik $\rightarrow$ rzeczownik (nominalizacja)

Au calice éternel qu’épuisait ma folie.

W wiecznym kielichu, karmie mego obłąkania. (wiersz 2)

3) rzeczownik $\rightarrow$ przymiotnik

Sest-elle réunie à la splendeur de Dieu?

Dołączyć zdołała do Boga wspaniałego? (wiersz 12)

4) wyrażenie przyimkowe $\rightarrow$ przysłówek

Amour, qui traversait l'univers d'un coup d'aile.

Miłość, co cały wszechświat zwinnie przemierzała. (wiersz 3)

5) imiesłów czasu przeszłego $\rightarrow$ rzeczownik

Marqué de leur génie et fait à leur image.

Dowód ich geniuszu, na ich obraz stworzone. (wiersz 5) 
6) imiesłów czasu przeszłego $\rightarrow$ czasownik

Et maintenant, ô morts, le supplice achevé.

A teraz, o umarli, mękę skończyliście. (wiersz 12)

\section{Inwersja}

Le grave enseignement des vertus éternelles.

Wartości nieśmiertelnych ważne nauczanie. (wiersz 8)

Que pour s'épanouir dans l'ordre et la clarté!

By je w porządku i jasności rozwijano! (wiersz 5)

Et votre âme, brisant l'enveloppe mortelle.

A wasza dusza bez przykrywki doczesności. (wiersz 12)

\section{Amplifikacje}

Vois quel monde immortel de leurs mains est sorti.

Zobacz, jaki nieśmiertelny świat nam oddali. (wiersz 5)

\section{Redukcja}

Qu’importe le réveil? Le songe était sublime.

Cóż znaczy przebudzenie? Wielkie to marzenie. (wiersz 12)

Podsumowując, w tłumaczeniu poezji Leconte de Lisle’a wyzwaniem stało się dla mnie zachowanie pewnych wyznaczników poetyckości (Barańczak 2004): waloru artystycznego wierszy, warsztatu poetyckiego, sensu i ducha wierszy, kontekstu kulturowego i historycznego oraz strony technicznej: liczby zwrotek, liczby wersów w zwrotce oraz rymu i układu sylabicznego (zachowałam w przekładzie oryginalną liczbę zwrotek i wersów, by nie zaburzać architektury wiersza i móc w pełni wyrazić niesioną przez niego treść). Najbardziej jednak zależało mi na tym, aby zachować te same walory estetyczne, które cechują tekst oryginału. Starałam się poprawnie stosować środki wyrazu poetyckiego w języku docelowym przy zachowaniu sensu wierszy. Najtrudniejsze jednak okazało się wczucie w ducha poezji, na którego składają się elementy nieuchwytne i niemierzalne. Tłumacz bowiem, w szczególności tłumacz wierszy, powinien niejako „intelektualnie” wniknąć w świat ekspresji poety, który najczęściej żył w innym niż on czasie i miejscu.

Żywię głęboką nadzieję, że w przekładzie poezji udało mi się w zadowalającym stopniu zmierzyć z wymienionymi powyżej wyzwaniami, a co za tym idzie - iż ta trudna, a momentami także żmudna praca związana z tłumacze- 
niem wierszy - która jednocześnie przyniosła mi wiele satysfakcji i radości - przyczyni się do pełniejszej recepcji zarówno twórczości Leconte de Lisle’a, jak i Henryka Elzenberga w Polsce.

\section{Literatura}

Adamski, J., 1966, Historia literatury francuskiej, Wrocław-Warszawa-Kraków.

Baluch, J., 2007, Wiersz i przekład, Kraków.

Barańczak, S., 1994, Ocalone w tłumaczeniu. Szkice o warsztacie tłumacza poezji z dołaczeniem małej antologii przekładów, Poznań.

Brzozowski, J., 2011, Stanać po stronie tłumacza. Zarys poetyki opisowej przekładu, Kraków.

Elsenberg, H., 1909, Le sentiment religieux chez Leconte de Lisle, Paris.

Elzenberg, H., 2013, Odczuwanie religii u Leconte de Lisle'a, przeł. P. Bobowska-Nastarzewska, Toruń.

Głowiński, M., Kostkiewiczowa, T., Okopień-Sławińska, A., Sławiński, J., 1998, „Rym”, [w:] Słownik terminów literackich, Wrocław-WarszawaKraków, s. 487-492.

Głowiński, M., Okopień-Sławińska A., Sławiński J., 1967, Zarys teorii literatury, Warszawa.

Jarrety, M. (red.), 2001, Dictionnaire de Poésie de Baudelaire à nos jours, Paris. Jarrety, M. (red.), 1997, La poésie française du Moyen Âge jusqu’à nos jours, Paris.

Jasińska, M., 1956, Dwunastozgłoskowiec, [w:] Sylabizm, Z. Kopczyńska, M. R. Mayenowa (red.), Wrocław, s. 353-380.

Kopczyńska, Z., 1956, Trzynastozgłoskowiec, [w:] Sylabizm, Z. Kopczyńska, M. R. Mayenowa (red.), Wrocław, s. 380-427.

Kopczyńska, Z., Dobrzyńska T., Pszczołowska L., 2007, Znaczenie wyboru formy wiersza. Trzy studia, Warszawa.

Krysztofiak, M., 1996, Przekład literacki we współczesnej translatoryce, Poznań.

Lam, S. (red.), 1933, Wielka literatura powszechna, t. 2, Kraków.

Legeżyńska, A., 1997, „Tłumacz jako drugi autor - dziš”, [w:] Przekład literacki. Teoria. Historia. Współczesność, A. Nowicka-Jeżowa, D. Knysz-Tomaszewska (red.), Warszawa, s. 40-50.

Lewicki, R., 2012, „Czynnik kulturowy a podstawowe cechy przekładu”, [w:] Przekład. Język. Kultura, R. Lewicki (red.), Lublin, s. 73-79. 
Orizet, J., 2007, Anthologie de la poésie française, Paris.

Pszczołowska, L., 1972, Rym, Wrocław-Warszawa-Kraków-Gdańsk.

Skibińska, E., 1999, Przekład a kultura. Elementy kulturowe we francuskich tłumaczeniach „Pana Tadeusza”, Wrocław.

Steiner, G., 2007, „Przekład jako conditio humana”, [w:] Przekładając nieprzekładalne. O wierności, O. Kubińska, W. Kubiński (red.), Gdańsk.

Święch, J., 1997, „Przekład na warsztacie badacza literatury”, [w:] Przekład literacki. Teoria. Historia. Współczesność, A. Nowicka-Jeżowa, D. Knysz-Tomaszewska (red.), Warszawa, s. 51-67.

Tyburski, W., 2006, Elzenberg, Warszawa.

\section{Translation of poetry as a challenge for the translator - considerations based on the author's own translations of poems of the $19^{\text {th }}$ century French poet Leconte de Lisle}

\section{Summary}

The subject of the paper is the presentation of a number of the author's observations related to the translation of poetry from French into Polish on the example of translation of rhymed poems by Leconte de Lisle. The poems were included in a $\mathrm{PhD}$ thesis written in French in 1909 by a Polish philosopher Henri Elsenberg entitled Le sentiment religieux chez Leconte de Lisle (The Religious Feeling in Leconte de Lisle). The work as well as the poetry of Leconte de Lisle quoted in it were translated by the author of the paper into Polish. The author's focus of interest is primarily on the issue of rhymes and the structure of syllables in poetry translation.

Keywords: literary translation, translation of poetry, translation strategy

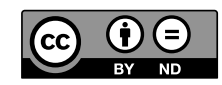


